\title{
Influence of Irreversible Hydrogen on the Fatigue Strength in Cold Drawn High Strength Steel*
}

\author{
Kohji MINOSHIMA $^{* *}$, Masanori NAKATANI ${ }^{* *}$, Atsushi SUGETA $^{* * *}$
and Masayuki SAKIHARA \\ ${ }^{* *}$ Osaka University, \\ 2-1, Yamadaoka, Suita, Osaka, 565-0871, Japan \\ E-mail: k-minoshima@mech.eng.osaka-u.ac.jp \\ ${ }^{* * *}$ Hiroshima University, \\ 1-4-4, Kagamiyama, Higashi-Hiroshima, Hiroshima, 739-8527, Japan \\ E-mail: asugeta@hiroshima-u.ac.jp
}

\begin{abstract}
Slow strain rate tensile (SSRT) tests and fatigue tests were conducted to investigate the influence of irreversible hydrogen on the quasi static SSRT strength and fatigue strength for cold drawn eutectoid steels which were cathodically hydrogen charged. Internal hydrogen states were changed as follows: (a) virgin sample, (b) the sample that contained both diffusible and irreversible hydrogen, and (c) the one that contained only irreversible hydrogen. The SSRT strength properties of only irreversible hydrogen contained sample were the same as that of virgin sample, whereas those of the sample having both diffusible and irreversible hydrogen were smaller than the others. This indicates that only the diffusible hydrogen caused hydrogen embrittlement under the quasi-static loading. Contrary to this, the fatigue strength of the sample having both diffusible and irreversible hydrogen was lower than that of virgin sample. However, the influence of irreversible hydrogen on the fatigue strength was unclear since $S-N$ curves had a large scatter. This is due to the fact that the fatigue crack was initiated at internal inclusion. Therefore, the fatigue strength was discussed based on the stress intensity factor, $\Delta K_{\text {inc }}$, calculated from stress and inclusion size. $\Delta K_{\text {inc }}$ giving the same $N_{\mathrm{f}}$ decreased in the order of virgin sample, irreversible hydrogen charged sample and the sample having diffusible and irreversible hydrogen, indicating irreversible hydrogen caused the fatigue strength degradation.
\end{abstract}

Key words: High Strength Steel, Fatigue, Diffusible Hydrogen, Irreversible Hydrogen, Thermal Desorption Spectrometry, Cold Drawing

\section{Introduction}

Despite of numerous researches on hydrogen embrittlement in a high strength steel, the mechanism ${ }^{(1) \sim(4)}$ remains unclear. Recently, Takai ${ }^{(5)}$ and Suzuki ${ }^{(6)}$ reported that hydrogen in steels exists as two kinds of states which are respectively called diffusible and irreversible hydrogen. While the former can diffuse at room temperature and contributes to hydrogen embrittlement under static loading, the latter does not influence the static strength because of high binding energy between hydrogen and its trap site ${ }^{(5)}$. Under cyclic loading, diffusible hydrogen decreases the fatigue strength such as the fatigue $\operatorname{limit}^{(7)}$ and the threshold stress intensity factor ${ }^{(8)}$. However, the influence of irreversible hydrogen on the fatigue strength in steels has not been clarified so far.

\footnotetext{
${ }^{*}$ Received 15 July, 2008 (№. 08-0475) Japanese Original : Trans. Jpn. Soc. Mech. Eng., Vol. 73, No. 725, A (2007), pp.118-124 (Received 7 Aug., 2006) [DOI: 10.1299/jmmp.2.1436]
} 
In this paper, the fatigue tests for the specimens under various hydrogen states were conducted to investigate the influence of irreversible hydrogen on the fatigue strength and fracture behavior. We also discussed differences in fatigue strength degradation between hydrogen trapping states that are diffusible and irreversible hydrogen.

\section{Experimental procedures}

The material used in the present study was a cold drawn eutectoid steel wire which consisted of the heavy deformed pearlitic microstructure as shown in Fig. 1. Tables 1 and 2 respectively show the chemical composition and mechanical properties. Figure 2 shows the shape and dimensions of the center part of a specimen for slow strain rate tensile (SSRT) tests and fatigue tests. The specimen surface was electrolytically polished to remove the work-hardening layer.

Hydrogen was charged by a cathodic charging technique in $0.2 \mathrm{~mol} / \mathrm{L} \mathrm{CH}_{3} \mathrm{COOH}+$ $0.17 \mathrm{~mol} / \mathrm{L} \mathrm{CH}_{3} \mathrm{COONa}$ buffer solution $(\mathrm{pH}=4.8)$. The current density was kept constant at $500 \mathrm{~A} / \mathrm{m}^{2}$ with charging time of $6 \mathrm{~h}$. Thermal desorption spectrometry (TDS) analysis were conducted in the temperature range from room temperature to $500{ }^{\circ} \mathrm{C}$ to analyze the hydrogen desorption behavior with a heating rate of $100^{\circ} \mathrm{C} / \mathrm{h}$.

SSRT tests were conducted at a tensile displacement rate of $3.3 \times 10^{-5} \mathrm{~mm} / \mathrm{s}$ to investigate the influence of diffusible and irreversible hydrogen on the static strength. Fatigue tests were also performed at a stress ratio $R=0$ and a stress cyclic frequency of 30

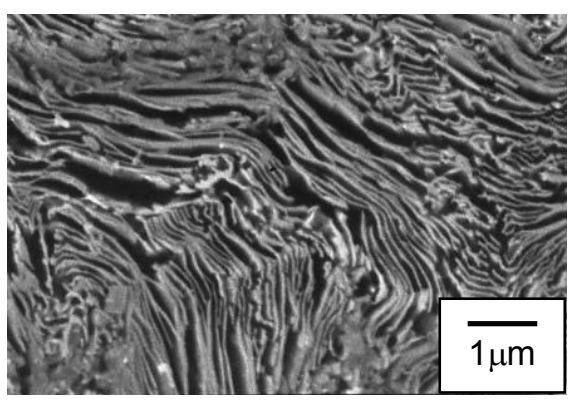

(a) Transverse section

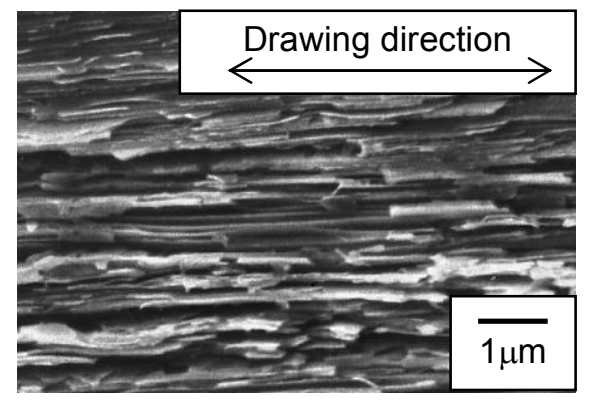

(b) Longitudinal section

Fig. 1 SEM images of microstructure.

Table 1 Chemical composition (mass \%).

\begin{tabular}{|c|c|c|c|c|c|c|}
\hline $\mathrm{C}$ & $\mathrm{Si}$ & $\mathrm{Mn}$ & $\mathrm{P}$ & $S$ & $\mathrm{Cu}$ & $\mathrm{Ni}$ \\
\hline 0.80 & 0.17 & 0.52 & 0.008 & 0.004 & 0.01 & 0.01 \\
\hline $\mathrm{Cr}$ & $\mathrm{Al}$ & Mo & $\mathrm{N}$ & $\mathrm{O}$ & $\mathrm{Fe}$ & \\
\hline 0.02 & 0.001 & 0.01 & 0.0036 & 0.0040 & bal. & \\
\hline
\end{tabular}

Table 2 Mechanical properties.

\begin{tabular}{|c|c|}
\hline Tensile strength [MPa] & Reduction of area [\%] \\
\hline 2040 & 39 \\
\hline
\end{tabular}

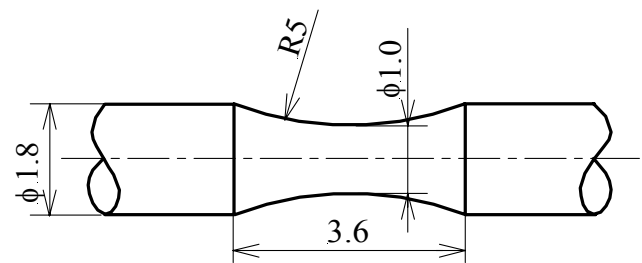

Fig. 2 Shape and dimensions of the center part of a specimen. 
$\mathrm{Hz}$ using an electro-hydraulic servo-controlled fatigue testing machine. To evaluate the influence of diffusible and irreversible hydrogen on the fatigue strength, internal hydrogen states were changed as follows: (a) virgin sample. (b) continuous hydrogen charging sample, which was continuously charged during the test after pre-charge for $6 \mathrm{~h}$. This sample contained both diffusible and irreversible hydrogen. (c) irreversible hydrogen charged sample, which was conditioned for $72 \mathrm{~h}$ in dry air after hydrogen pre-charge, and therefore it contained only irreversible hydrogen. The SSRT and fatigue tests of a virgin and an irreversible hydrogen charged samples were conducted in dry air (dew point: $-67^{\circ} \mathrm{C}$ ) to prevent hydrogen from entering the sample from the testing environment.

\section{Experimental results and discussion}

\section{1 Hydrogen desorption properties}

Figure 3 shows the hydrogen desorption profiles obtained by TDS analysis. Virgin sample hardly desorbed hydrogen as shown by dotted line. After hydrogen charge, two peaks of hydrogen desorption, shown by dashed line, appeared at $75{ }^{\circ} \mathrm{C}$ and $280{ }^{\circ} \mathrm{C}$, respectively. When the sample was conditioned in dry air for $60 \mathrm{~h}$ after hydrogen charge, the hydrogen desorption peak at $75{ }^{\circ} \mathrm{C}$ disappeared. This means that the hydrogen desorbed out of the sample during $60 \mathrm{~h}$ conditioning in dry air. On the other hand, hydrogen desorption peak at $280{ }^{\circ} \mathrm{C}$ hardly changed after 7 day conditioning. These results indicate that hydrogen desorbed at peak temperature of $75{ }^{\circ} \mathrm{C}$ and $280{ }^{\circ} \mathrm{C}$ correspond to diffusible and irreversible hydrogen, respectively. After hydrogen charge, the diffusible and irreversible hydrogen contents were $1.8 \mathrm{ppm}$ and $2.0 \mathrm{ppm}$ when we defined hydrogen that desorbed below and over $200{ }^{\circ} \mathrm{C}$ as diffusible and irreversible hydrogen, respectively.

The hydrogen trap site in a heavy deformed pearlitic microstructure was reported as follows $^{(5)}$ : a trap site of diffusible hydrogen corresponds to multiple sites such as vacancies, vacancy clusters, strain field of dislocations, dislocation cores and grain boundaries. In contrast with this, a trap site of irreversible hydrogen corresponds to a strained interface between ferrite and cementite.

\section{2 Influence of internal hydrogen on the SSRT strength}

Figure 4 shows stress-displacement curves for the samples having various internal hydrogen states. The elongation at fracture and tensile strength of continuous hydrogen charging sample that contained both diffusible and irreversible hydrogen decreased compared with those of a virgin sample. On the other hand, irreversible hydrogen charged

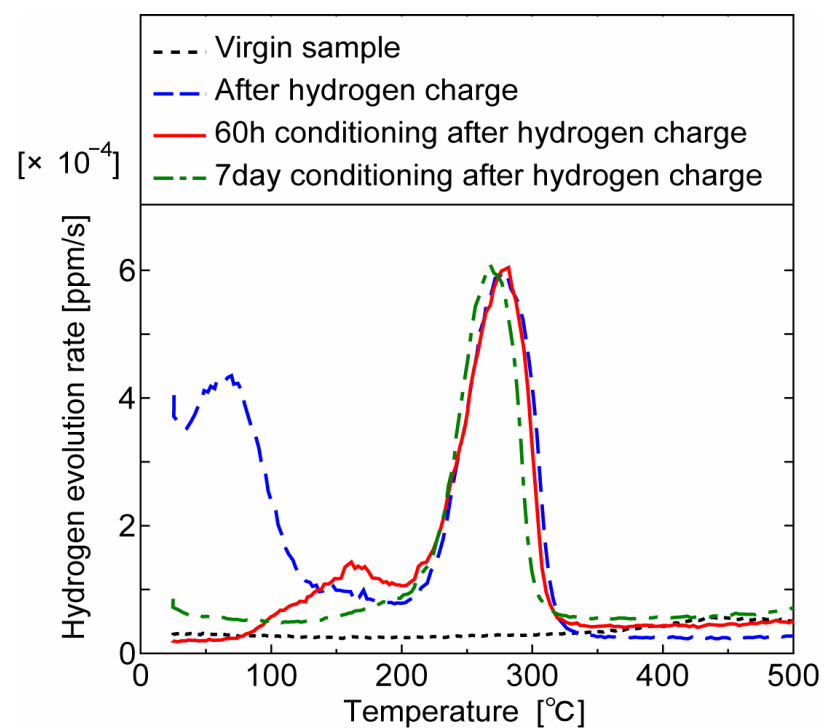

Fig. 3 Hydrogen evolution rate as a function of temperature measured by TDS. 
sample showed almost the same elongation at fracture and tensile strength as those of virgin sample.

Figure 5 shows scanning electron microscope (SEM) images of fracture surfaces obtained by SSRT. A cup-and-corn type fracture, which is a typical feature of ductile fracture, was observed for both virgin sample (see Fig. 5(a)) and irreversible hydrogen charged sample (see Fig. 5(e)). A crack was initiated at the surface for the continuous hydrogen charging sample as shown in Fig. 5(c). In the virgin and irreversible hydrogen charged sample, dimples were observed: see Figs. 5(b) and (f). On the other hand,

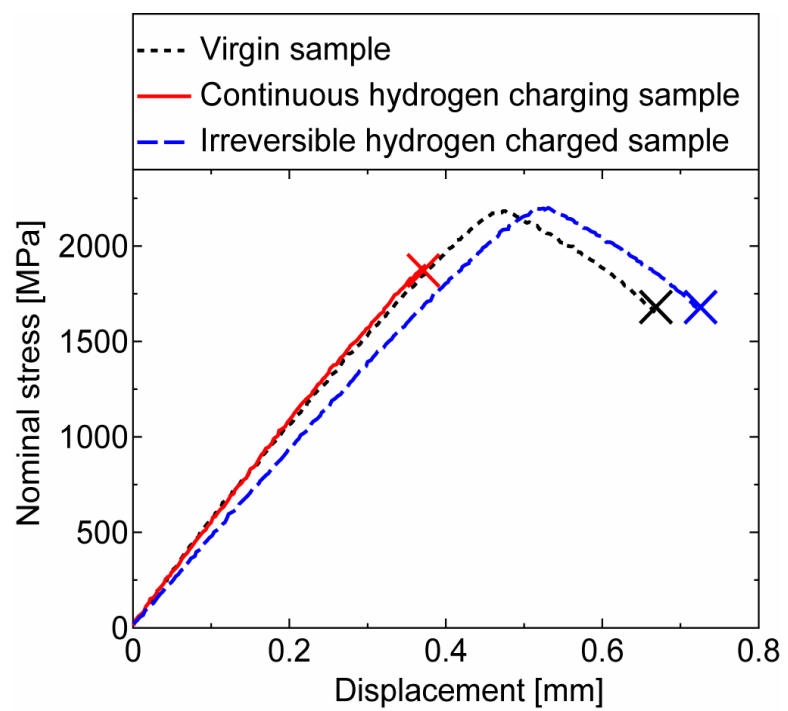

Fig. 4 Influence of hydrogen charge on the SSRT stress-displacement curves of SSRTs.
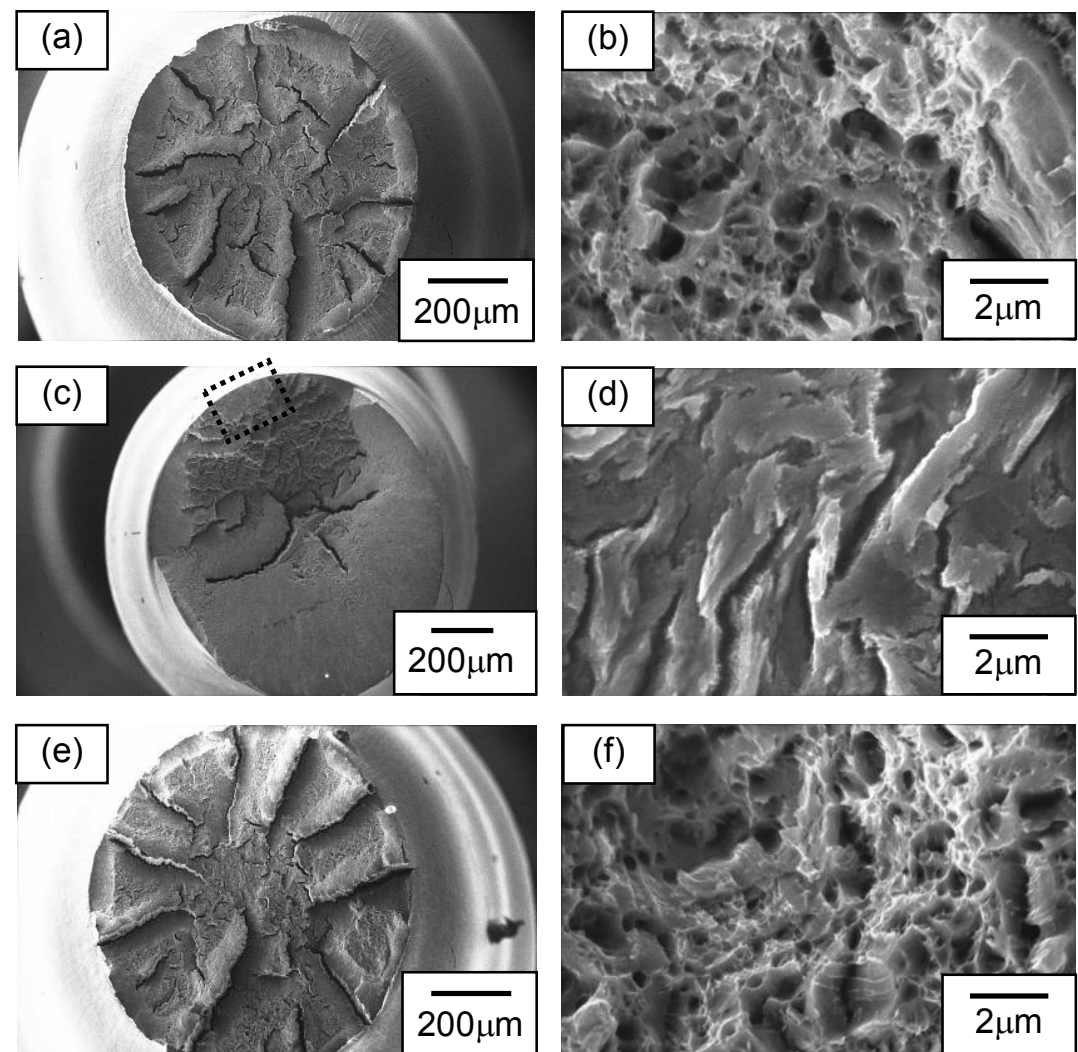

Fig. 5 Fracture surfaces of SSRT specimen. (a) and (b) virgin sample; (c) and (d) continuous hydrogen charging sample; (e) and (f) irreversible hydrogen charged sample. 
quasi-cleavage fracture and secondary cracks dominated over the fracture surface of the continuous hydrogen charging sample, which showed a decrease in SSRT strength by hydrogen. These results indicate that diffusible hydrogen causes a decrease in the static strength, while irreversible hydrogen does not.

\section{3 Evaluation of the influence of internal hydrogen on the fatigue strength}

Figure 6 shows the influence of internal hydrogen states on the $S-N$ curves. A superscript "*" indicates that a sample was first subjected to $\Delta \sigma$ of $1400 \mathrm{MPa}$ for $10^{7}$ cycles, and then the applied stress was increased to $1600 \mathrm{MPa}$ until final failure. The subscripts (a) $\sim(d)$ indicate that the same sample used for this low-high two-step fatigue test. For continuous hydrogen charging sample, the fatigue life and the fatigue limit decreased compared with those of a virgin sample. However, the influence of irreversible hydrogen on the fatigue strength is not clear because of a large scatter. The reason is that the fatigue crack was initiated at an inclusion in a sample. Therefore we evaluated the fatigue strength in terms of stress intensity factor range which was calculated by using the following equation ${ }^{(9)}$.

$$
\Delta K_{\mathrm{inc}}=0.5 \Delta \sigma \sqrt{\pi \sqrt{\text { area }_{\text {inc }}}}
$$

where $\Delta K_{\text {inc }}$ is stress intensity factor range $\left(\mathrm{MPam}^{1 / 2}\right), \Delta \sigma$ is the applied stress range $(\mathrm{MPa})$, and $\operatorname{area}_{\mathrm{inc}}$ is the projected size of an inclusion $\left(\mathrm{m}^{2}\right)$. Figure 7 shows the relationship

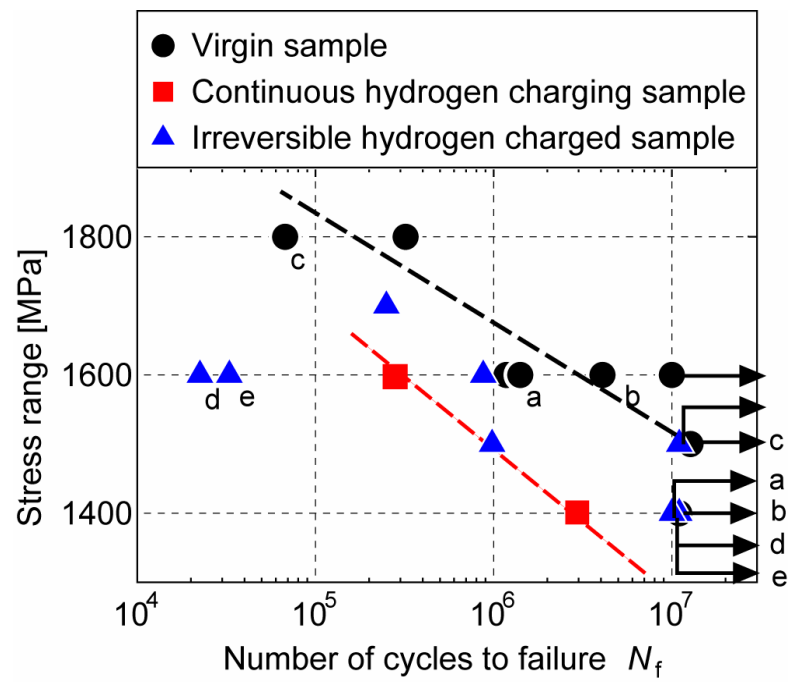

Fig. $6 \quad S$ - $N$ curves.

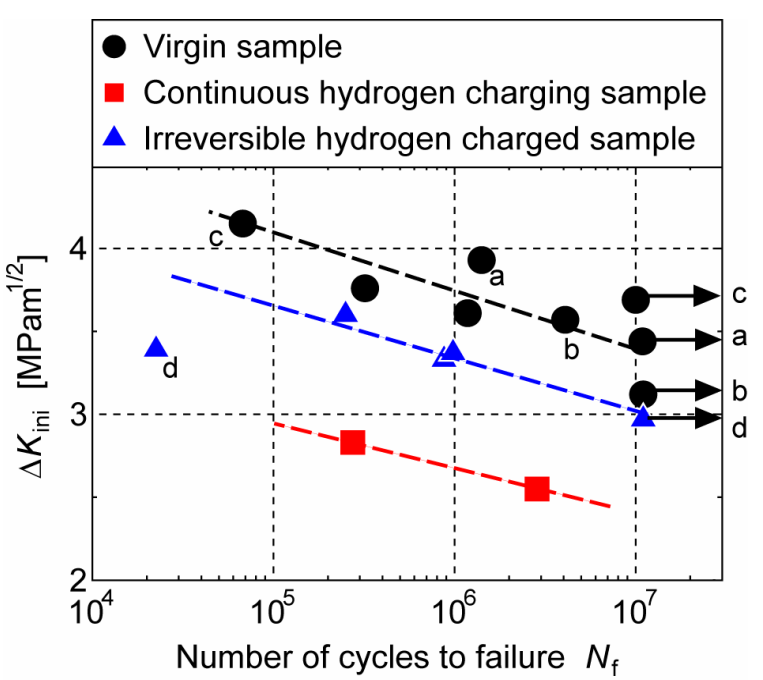

Fig. 7 Relationship between $\Delta K_{\text {inc }}$ and $N_{\text {f. }}$. 
between stress intensity factor range $\Delta K_{\mathrm{inc}}$ and the number of cycles to failure $N_{\mathrm{f}}$. The data with the subscript "d" in Fig. 6 is excluded in Fig. 7 because the fracture surface suffered from post-corrosion, and the crack initiation site could not be verified. Irrespective of internal hydrogen state, $N_{\mathrm{f}}$ increased as $\Delta K_{\text {inc }}$ decreased, and $\Delta K_{\text {inc }}$ giving the same $N_{\mathrm{f}}$ became smaller in the order of virgin sample, irreversible hydrogen charged sample and continuous hydrogen charging sample, which indicates that the crack initiation and propagation were promoted by irreversible hydrogen, and were more by diffusible hydrogen. When we defined $\Delta K_{\text {inc }}$ at which a sample did not fracture up to $10^{7}$ cycles as the threshold stress intensity factor, the value of irreversible hydrogen charged sample was smaller than that of virgin sample. Therefore, it must be noted that a decrease in the threshold stress intensity factor was brought about even by only irreversible hydrogen.

The fracture surface was observed by a field emission type scanning electron microscope (FESEM). Figure 8 shows fatigue fracture surface of three different internal hydrogen states. As mentioned before, the fatigue crack was initiated at an internal inclusion irrespective of internal hydrogen state and stress level. From the results of the macroscopic observations, the fracture surface of continuous hydrogen charging sample (Fig. 8(c)) looked rough compared with those of virgin sample (Fig. 8(a)) and irreversible hydrogen charged sample (Fig. 8(e)). From a microscopic view point, the fracture surface of a virgin sample showed ductile transgranular fracture, see Fig. 8(b). In the case of continuous
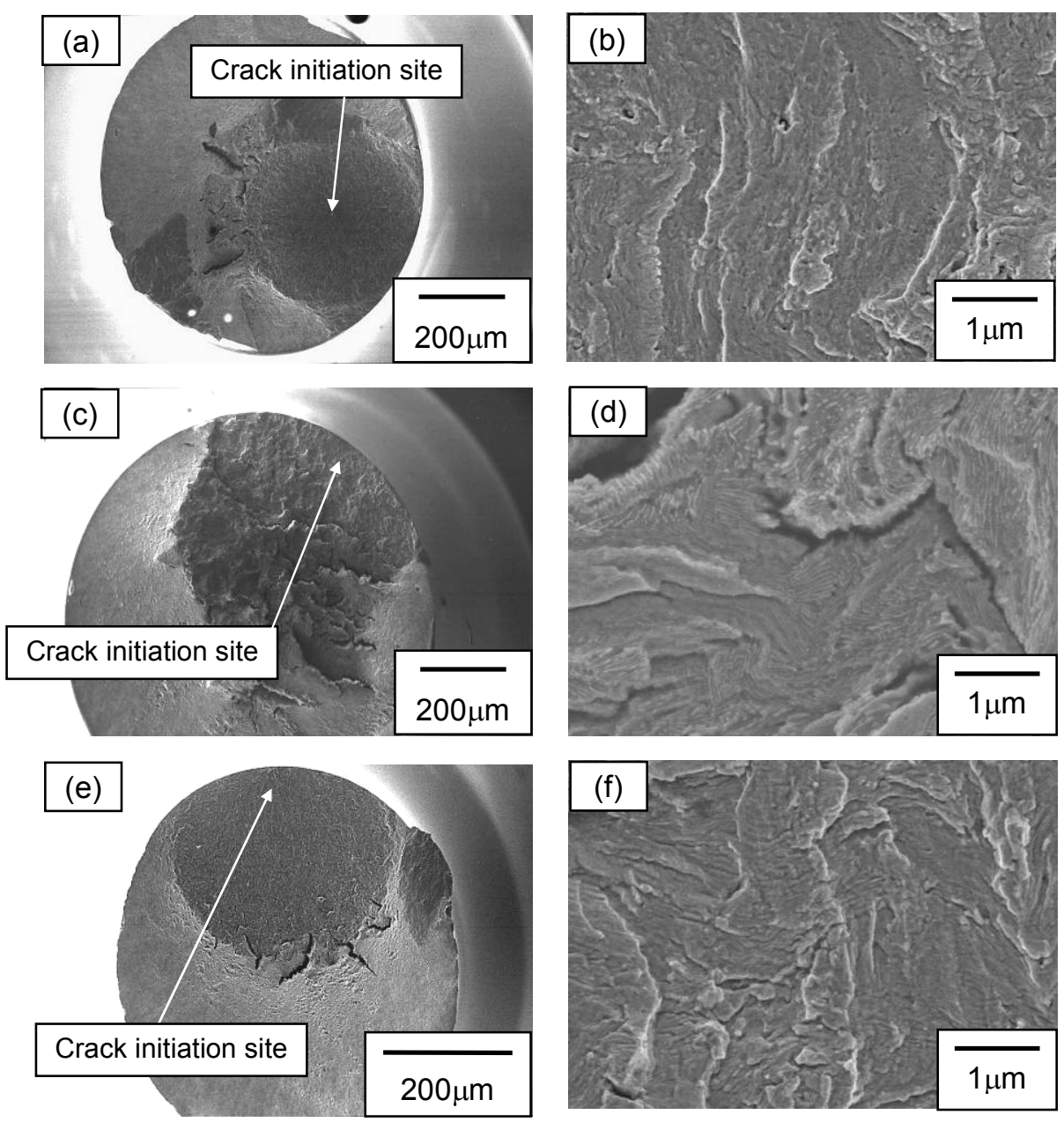

Fig. 8 FESEM images of fatigue fracture surfaces. (a) and (b) virgin sample; (c) and (d) continuous hydrogen charging sample; (e) and (f) irreversible hydrogen charged sample. Figures (b), (d) and (f) are magnified photographs of the area $50 \mu \mathrm{m}$ away from the crack initiation site shown in Figures (a), (c) and (e), respectively. 

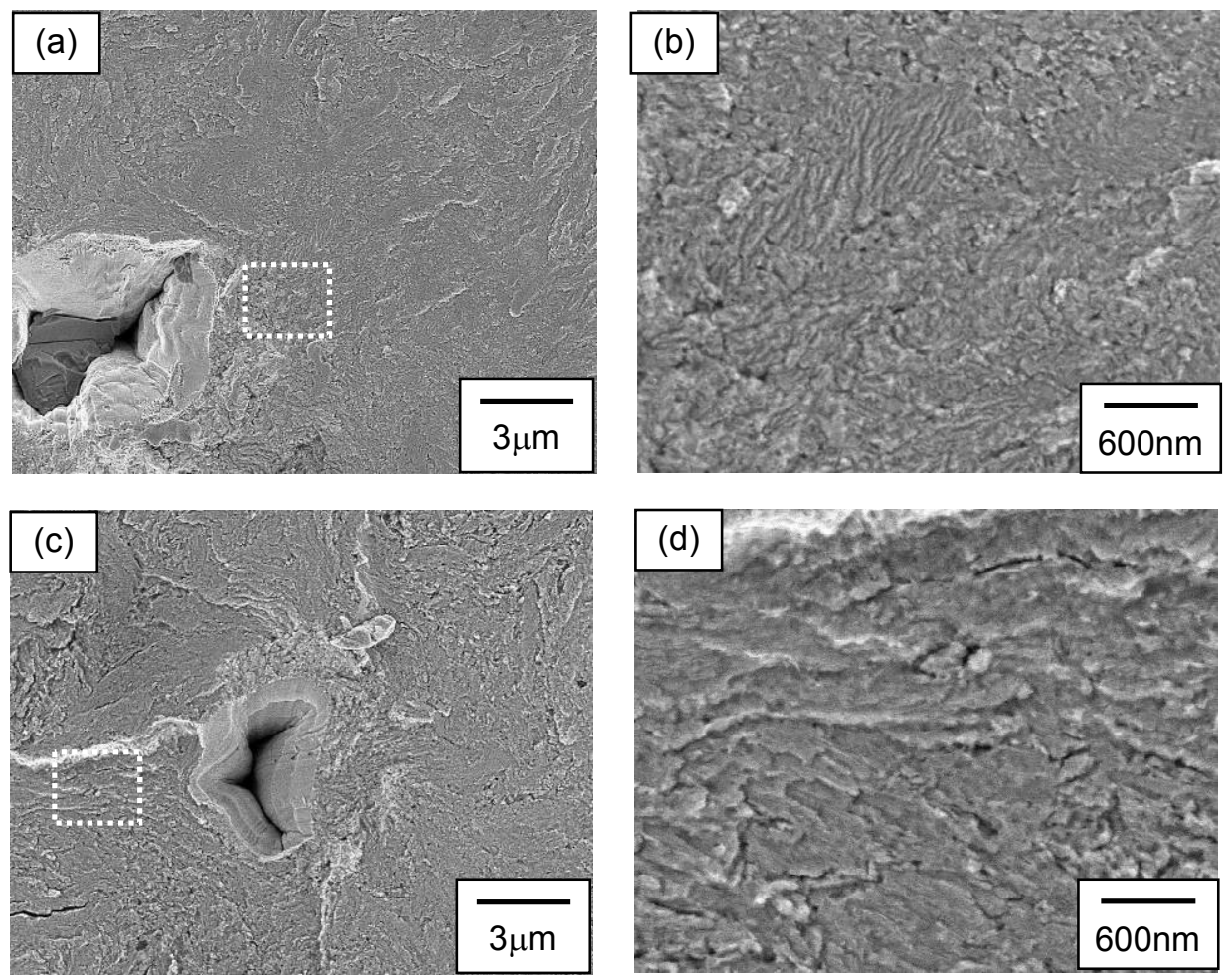

Fig. 9 FESEM images of fatigue fracture surfaces near crack initiation site. (a) and (b) virgin sample; (c) and (d) irreversible hydrogen charged sample. Figures (b) and (d) are magnified photographs of the square area shown in Figures (a) and (c), respectively.

hydrogen charging sample, the fracture surface showed a brittle feature showing cleavage fracture having angular steps, the secondary crack and cleavage fracture related with pearlitic microstructures, see Fig. 8(d). In contrast with these two, the fracture surface of irreversible hydrogen charged sample had an intermediate feature but looked brittle.

To investigate the influence of irreversible hydrogen on the fatigue fracture, the fracture surfaces near the crack initiation site in virgin sample and irreversible hydrogen charged sample were closely observed by FESEM. The results are shown in Fig. 9. In the case of the virgin sample, the fine granular fracture surface, which is different from so called optical dark area $(\mathrm{ODA})^{(10)}$ or fine granular area $(\mathrm{FGA})^{(11)}$, was observed around the crack initiation site, see Fig. 9(b). For the irreversible hydrogen charged sample, however, the fracture surface exhibited different fracture surface morphology, showing quasi-cleavage facets with some steps, which is similar to Figs. 5(d) and 8(d). These results suggest that a decrease in the fatigue strength is caused not only by diffusible hydrogen but also by irreversible hydrogen, which does not cause a decrease in strength under static loading. Note that a mechanism for decreasing the fatigue strength by irreversible hydrogen requires further investigation.

\section{Conclusions}

We investigated the influence of irreversible hydrogen on the slow strain rate tensile strength and fatigue strength of cold drawn high strength steel wire. The investigation yielded the following conclusions.

1. Thermal desorption spectrometry analysis of hydrogen charged sample showed two hydrogen desorption peaks at $75^{\circ} \mathrm{C}$ and $280^{\circ} \mathrm{C}$. The former disappeared by $60 \mathrm{~h}$ conditioning in dry air, while the later remained. This means that the hydrogen desorption peaks at $75^{\circ} \mathrm{C}$ and $280^{\circ} \mathrm{C}$ corresponds to diffusible and irreversible 
hydrogen, respectively.

2. The SSRT strength and its elongation at fracture decreased by diffusible hydrogen, and the fracture surface became brittle. On the other hand, irreversible hydrogen did not influence the SSRT properties, and the fracture surface was ductile. These yield that only diffusible hydrogen contributes to hydrogen embrittlement under quasi-static loading condition.

3. The fatigue crack was initiated from an internal inclusion irrespective of internal hydrogen state. A decrease in the fatigue strength was caused not only by diffusible hydrogen but also by irreversible hydrogen. The crack initiation and propagation were promoted by irreversible hydrogen, and more by diffusible hydrogen. The fatigue fracture surface of an irreversible hydrogen charged sample was brittle compared with a virgin sample. When the fatigue strength was evaluated in terms of stress intensity factor range calculated by the applied stress and the size of an inclusion that caused crack initiation, the threshold stress intensity was decreased not only by diffusible hydrogen but also by irreversible hydrogen.

\section{References}

(1) Oriani, R. A. and Josephic, P. H., Testing of the Decohesion Theory of Hydrogen-Induced Crack Propagation, Scripta Metallurgica, Vol. 6 (1972), pp. 681-688.

(2) S. P. Lynch, Environmentally Assisted Cracking: Overview of Evidence for an AdsorptionInduced Localized-Slip Process, Acta Metallurgica, Vol. 36, No. 10 (1988), pp. 2639-2661.

(3) Birnbaum, H. K. and Sofronis, P., Hydrogen-Enhanced Localized Plasticity-a Mechanism for Hydrogen-Related Fracture, Materials Science and Engineering A, Vol. 176 (1994), pp. 191-202.

(4) Nagumo, M., Ishikawa, T., Endoh, T. and Inoue, Y., Amorphization Associated with Crack Propagation in Hydrogen-Charged Steel, Scripta Metarialia, Vol. 49 (2003), pp. 837-842.

(5) Takai, K. and Watanuki, R., Hydrogen in Trapping States Innocuous to Environmental Degradation of High-Strength Steels, ISIJ International, Vol. 43, No. 4 (2003), pp. 520-526.

(6) Suzuki, S., Ishii, N. and Tsuchida, Y., Diffusible Hydrogen Behavior in Pre-strained High Strength Steel, Journal of the Iron \& Steel Institute of Japan, Vol. 80, No. 11 (1994), pp. 855-859.

(7) Murakami, Y. and Nagata, J. Effect of Hydrogen on High Cycle Fatigue Failure of High Strength Steel, SCM435, Journal of the Society of Materials Science, Japan, Vol. 54, No. 4 (2005), pp. 420-427.

(8) Yanagihara, K., Ohyanagi, S., Kubota, M., Sakae, C. and Kondo, Y., Effects of Crack Size, Stress Ratio and Hydrogen on the Near Threshold Fatigue Crack Propagation of High Strength Steel, Journal of the Society of Materials Science, Japan, Vol. 54, No. 12 (2005), pp. 1237-1243.

(9) Murakami, Y., Kodama, S. and Konuma, S., Quantitative Evaluation of Effects of Nonmetallic Inclusions on Fatigue Strength of High Strength Steel, Transactions of the Japan Society of Mechanical Engineers, Series A, Vol. 54, No. 500 (1988), pp. 688-696.

(10) Murakami, Y., Nomoto, T., Ueda, T. and Murakami, Y., On the Mechanism of Fatigue Failure in the Superlong Life Regime ( $\mathrm{N}>10^{7}$ cycles). Part I: Influence of Hydrogen Trapped by Inclusions, Fatigue and Fracture of Engineering Materials and Structures, Vol. 23, No. 11 (2000), pp. 893-902.

(11) Sakai, T., Sato, Y. and Oguma, N., Characteristic $S-N$ Properties of High-carbonchromium-bearing Steel under Axial Loading in Long-life Fatigue, Fatigue and Fracture of Engineering Materials and Structures, Vol. 25, No. 8-9 (2002), pp. 765-773. 